\title{
NEUROTRANSMITTER TRANSPORTERS: Recent Progress ${ }^{1}$
}

\author{
Susan G. Amara \\ Vollum Institute for Advanced Biomedical Research, Oregon Health \\ Sciences University, Portland, Oregon 97201
}

\author{
Michael J. Kuhar \\ Neurosciences Branch, Addiction Research Center, National Institute on \\ Drug Abuse, Baltimore, Maryland
}

KEY WORDS: neurotransmitter reuptake, synaptic signal termination, uptake

\section{INTRODUCTION}

It has been known for many years that neurons and glia can accumulate neurotransmitters by a sodium dependent cotransport process that is, in many respects, similar to systems present in most cells for concentrating metabolites. By cotransporting a solute with sodium, the energy stored in transmembrane electrochemical gradients can be used to drive the solute into the cell (reviewed in Kanner \& Schuldiner 1987; Trendelenburg 1991). A special appreciation of the neurotransmitter cotransport systems has developed from studies, which indicate the existence of multiple uptake systems, each relatively selective for a specific neurotransmitter. Table 1 presents a list of brain uptake systems that have been identified. These transport activities are localized within the synaptic membranes of neurons that use the same transmitter and are probably the most important mechanism for terminating synaptic transmission. Many of these transporters

\footnotetext{
${ }^{1}$ The US government has the right to retain a nonexclusive, royalty-free license in and to any copyright covering this paper.
} 
Table 1 Neurotransmitter (candidates) have high affinity transport systems

\begin{tabular}{ll}
\hline Dopamine & GABA \\
Norepinephrine & Glycine \\
Serotonin & Taurine \\
Glutamate & Proline \\
Aspartatc & Adenosine
\end{tabular}

or reuptake systems have been implicated as important sites for drug action. The augmentation of synaptic activity by selective inhibitors of specific sodium-dependent monoamine transport forms the basis for the mechanism of action of clinically important antidepressant drugs. Recently, interest in these uptake systems has peaked, because these same transporters are the primary site of action of cocaine and other stimulant drugs of abuse. Many of these topics have been reviewed (Amara \& Pacholczyk 1991; Horn 1990; Iversen 1975; Kanner \& Schuldiner 1987; Snyder 1970; Trendelenburg 1991).

Most recently, several of these plasma membrane transporters have been cloned with the resulting promise of rapid new advances in understanding the mechanisms of neurotransmitter reuptake. In this article, we review this and other topics. We focus on more recent developments on neurotransmitter transporters and provide some historical data. This review does not deal with uptake of neurotransmitters into intracellular vesicles, which has been reviewed elsewhere (Kanner \& Schuldiner 1987; Rudnick 1986; Winkler et al 1986).

\section{Neurotransmitter Uptake Is a Mechanism to Inactivate Released Transmitter}

The large body of experimental data that has led to the conclusion that transporters are a major mechanism for terminating synaptic transmission (see Iversen 1975) is beyond the scope of this review. As an overview, we present some of the classic data of norepinephrine.

Burn (1932) was one of the first to suggest that norepinephrine might be taken up by tissues. Many subsequent reports supported this notion. Axelrod and coworkers (Axelrod et al 1959; Whitby et al 1961) showed that tritiated norepinephrine and tritiated epinephrine were removed from circulation in animals after injections of small doses. These radiolabeled catecholamines accumulated in various peripheral tissues. The fact that the tritiated norepinephrine was found in tissues with the highest degree of sympathetic innervation suggested that the catecholamine was accumulating in sympathetic neurons. In support of this latter notion, a decrease 
in norepinephrine uptake was found after destruction of sympathetic neurons in various peripheral organs. For example, in rodents that had been given nerve growth factor antiserum to hinder the development of the sympathetic nervous system, the accumulation of tritiated norepinephrine was reduced in peripheral organs (Iversen et al 1966; Sjöqvist et al 1967; Zaimis et al 1965). Also, lesions of ascending noradrenergic pathways in brain resulted in a reduction of tritiated norepinephrine uptake by synaptosomal factions prepared from areas receiving these pathways (Kuhar 1973). Taken together, these and many other findings suggest the existence of an uptake mechanism in sympathetic neurons for accumulating catecholamines. This evidence was strengthened by additional autoradiographic and histochcmical studics.

Several sources provide evidence that the reuptake process terminates synaptically released norepinephrine. Especially important is the observation that inhibitors of norepinephrine metabolism do not potentiate noradrenergic neurotransmission, whereas drugs that inhibit the noradrenergic uptake system can have substantial enhancing effects on neurotransmission (Iversen 1967, 1975). Also, little or no norepinephrine overflows into perfusing fluids from various organs during sympathetic nerve stimulation; however, if inhibitors of norepinephrine uptake are present, a large increase in norepinephrine overflow occurs after sympathetic nerve stimulation (Brown \& Gillespie 1957). In tissues with dense sympathetic innervation, as much as $70-80 \%$ of released neurotransmitter may be recaptured under ordinary conditions (Iversen 1975).

The above evidence strongly supports the uptake hypothesis; over the years, similar experiments have been carried out with other neurotransmitter systems. In general, the results support this hypothesis for many neurotransmitters that have high affinity uptake systems in nerve terminals. Table 1 lists the various neurotransmitter candidates that have an associated high affinity transport system. Interestingly, acetylcholine is not present on the list; it is inactivated by enzymatic breakdown. There is, instead, a high affinity transport system for the precursor, choline (Kuhar \& Murrin 1978; Yamamura \& Snyder 1973).

\section{Transporters as Drug Receptors}

Powerful physiologic effects rcsult from the administration of drugs that block neurotransmitter reuptake. This observation not only supports the functional importance of transporters as described above, but has led to the exploration of transporter mechanisms and pharmacology by the drug industry to develop potentially useful therapeutic drugs. For example, a strong current interest in the serotonin transporter stems from the potent blocking actions that many antidepressant drugs, such as fluoxetine (Fuller 
\& Wong 1990) and imipramine (Langer \& Briley 1981), have at the serotonin transporter in brain. Imipramine binding sites are also interesting because their number is reduced in the platelets of depressed patients relative to controls (Langer \& Raisman 1983; Paul et al 1981). Other antidepressant drugs, such as the tricyclic antidepressant desipramine, are also inhibitors of norepinephrine uptake (Rehavi et al 1982). Although the precise role of transporters in the antidepressant action of these drugs is not yet known, the fact that so many drugs are active at these sites has resulted in a focus on transporters as a potential mechanism of action of these drugs.

Interest in the dopamine transporter also has recently increased, because of evidence that it may be the primary site of action or the "receptor" for psychostimulant drugs, such as cocaine (Bergman et al 1989; Ritz et al 1987; Spealman et al 1989). The data in support of this concept have been reviewed (Kuhar et al 1991).

The major classes of brain reuptake systems (see Figure 1) are defined by substrate and antagonist specificities, kinetic properties, and ionic requirements. Transporter antagonists have also provided evidence for

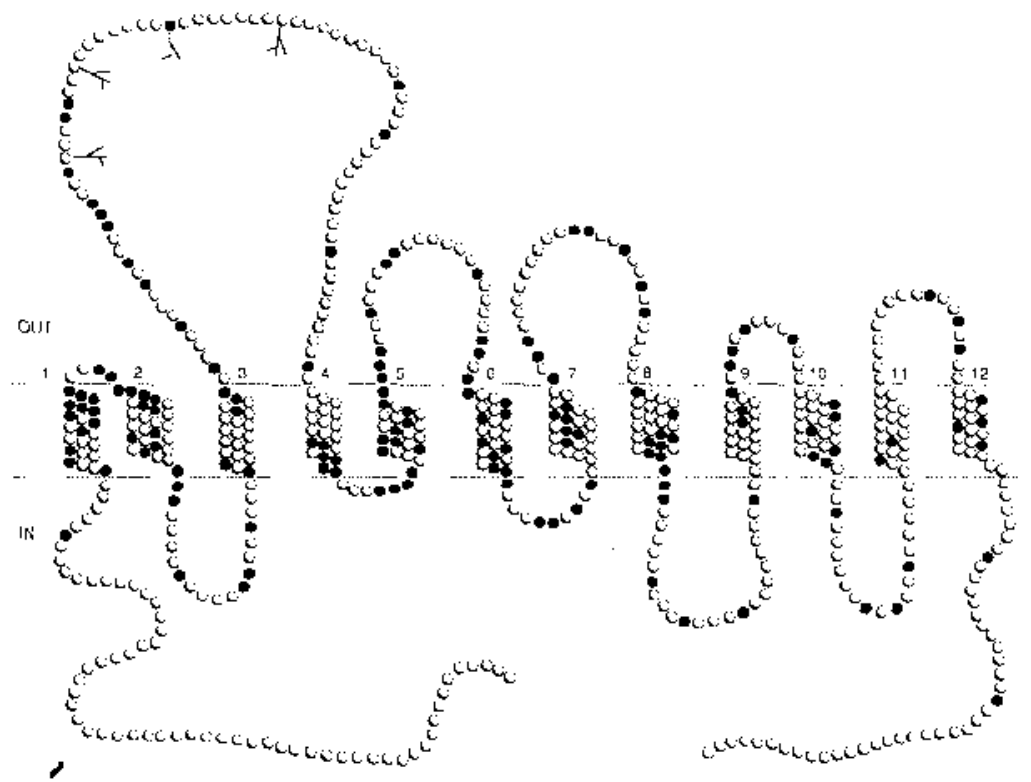

Figure 1 Model of the transmembrane topology of the dopamine transporter. Solid dots denote amino acid residues conserved between rat dopamine (DAT) (Kilty et al 1991; Shimada et al 1991a), human norepinephrine (NET) (Pacholczyk et al 1991), rat GABA (GAT) (Guastella et al 1990), rat serotonin (5-HTT) (Blakely et al 199 la), and canine betaine (BGT-1) (Yamauchi et al 1992) transporters. 
functionally distinct transporter subtypes within a class, particularly among the amino acid neurotransmitter transporters. At least two $\gamma$ aminobutyric acid (GABA) transport systems have been described, based upon differential sensitivity to cis-1,3-aminocyclohexane carboxylic acid (ACHC) (Bowery et al 1976) and $\beta$-alanine (Iversen \& Kelly 1975). It has been proposed that these subtypes represent distinct neuronal and glial transporters, but some studies contradict this hypothesis (Cummins et al 1982; Larsson et al 1986). Glial norepinephrine, serotonin, and glutamate uptake activities have also been described (Kimelberg \& Katz 1985, 1986; Kimelberg \& Pelton 1983; Roberts \& Watkins 1975), thus supporting the notion that glia may be important regulators of extracellular neurotransmitter concentrations.

\section{Solubilization, Purification, and Characterization of Transporters}

A number of transporters have been solubilized, (partially) purified, and reconstituted in different ways. Several transporter molecules with available binding ligands can be purified by using a relatively simple ligandbinding technique. For example, the choline transporter has been partially purified from rat brain by using tritiated hemicholinium-3 as a binding ligand (Yamada et al 1988). Similarly, the dopamine and neuronal serotonin transporters have been solubilized and partially purified by using ligand binding as an assay (Berger et al 1990; Biessen et al 1990; Graham et al 1991; Grigoriadis et al 1989; Lew et al 1991a; Sallee et al 1989). Transporters that do not have high-affinity binding ligands require more difficult reconstitution assays for purification. The glutamate transporter (Gordon \& Kanner 1988) and the sodium and chloride coupled glycine transporter (Lopez-Corcuera et al 1989) have been solubilized and partially purified in this way. In addition, the GABA transporter has been solubilized and reconstituted in proteoliposomes (Kanner et al 1989; Radian \& Kanner 1986). In general, studies have shown that neurotransmitter transporters are glycoproteins with apparent molecular weights ranging from 60,000 to $85,000 \mathrm{Da}$.

Although the availability of high-affinity ligands has greatly facilitated the study of the monoamine and choline carriers, none have been purified to homogeneity. This may partly be caused by their low abundance relative to the transporters for GABA and glutamate, the apparent major inhibitory and excitatory neurotransmitters in the central nervous system.

The ACHC-sensitive GABA transporter, which to date has been the most thoroughly studied transport activity, has generated evidence for a variety of biochemical, structural, and functional characteristics. GABA transporter has been immunocytochemically localized to both neuronal 
and glial processes in rat brain by using polyclonal antibodies generated against the purified carrier (Radian et al 1990). In addition, limited papain digestion of the purified $80 \mathrm{kD}$ transporter can generate one or more oligosaccharide-containing bands with apparent molecular weights of approximately $60 \mathrm{kD}$ (Kanner et al 1989). When repurified by lectin chromatography, these proteolytic fragments can reconstitute GABA transport in liposomes, which suggests that the deleted domains are not critical to the fundamental transportactivity of the protein. Reconstitution experiments that use synthetic liposomes have also explored the role of brain lipids in determining the basal transport activity; the results suggest that cholesterol must associate with the transporter in the membrane for optimal transport function (Shouffani \& Kanner 1990).

\section{Ionic Dependence and Electrogenic Properties of Transport}

Studies of transport mechanisms have demonstrated that the plasma membrane transporters are cotransporters (or symporters), which transport sodium and frequently chloride ions (Kuhar \& Zarbin 1978) along with the neurotransmitter (reviewed in Johnstone 1990). The accumulation of neurotransmitter is coupled to the cotransport of sodium ions down a concentration gradient, a process analogous to the active transport of many other substrates. For the ACHC-sensitive GABA carrier, kinetic experiments suggest an apparent stoichiometry in which the zwitterionic form of GABA is cotransported with 2.5 sodium ions and one chloride ion (Keynan \& Kanner 1988). Although the L-glutamate transporter is also sodium-coupled, chloride is not required. In addition, glutamate transport has an absolute dependence on internal potassium; accumulated evidence suggests that potassium ions are counter-transported as part of a mechanism for recycling carriers to the extracellular side of the membrane. This overall topic has been reviewed in detail (Kanner \& Schuldiner 1987) and is not reviewed further here.

An important aspect of the neurotransmitter transport process is that it is potentially electrogenic. For the sodium-dependent GABA and glutamate transporters, a net translocation of charges across the membrane and the process generates a current. These inward currents have been directly measured by using whole cell patch clamp analysis of glutamate uptake, in salamander retinal glial cells (Schwartz \& Tachibana 1990; Szatkowski et al 1990) and in skate horizontal cells (Malchow \& Ripps 1990). The technique has also enabled studies of internal and external ionic dependence, stoichiometry of transport, voltage dependence of transport, and the conditions that lead to reversal of the uptake (reviewed in Nicholls \& Attwell 1990). Interestingly, norepinephrine (Trendelenburg 1991), GABA (Schwartz 1982, 1987), and glutamate (Szatkowski et al 1990) 
carriers can function in reverse, thus transporting substrates out of the cell when external potassium concentration rises and the cell is depolarized. This reversal of uptake may explain observed instances of calciumindependent, nonvesicular glutamate and GABA release (for example, see Pin \& Bockaert 1989).

\section{MOLECULAR BIOLOGY OF NEUROTRANSMITTER TRANSPORTERS}

Recent molecular biologic studies of neurotransmitter transporters have greatly increased our understanding of the structure of these important synaptic proteins and provided insights into the mechanisms of their function.

\section{Expression in Xenopus Oocytes}

Xenopus oocytes have proven to be a useful heterologous expression system for characterizing neurotransmitter transport activities. They have been used to study endogenous brain mRNAs and have provided a basis for expression cloning strategies. The oocyte expression system remains an important analytical tool for characterizing the activities encoded by cloned cDNAs.

Sodium-dependent transport activity for GABA, glutamate, glycine, choline, serotonin, and dopamine has been expressed in Xenopus oocytes injected with mRNA isolated from discrete rat brain regions (Blakely et al 1988; Sarthy 1986). The expressed transport activities exhibit the same characteristics and pharmacology as the high-affinity, sodium-dependent transporters observed in brain slices and synaptosomal preparations. More recently, mRNA from $\mathrm{PC} 12$ cells, as well as transcripts from a rat midbrain cDNA library, have been used to direct the expression of cocaine-sensitive dopamine uptake in oocytes (Uhl et al 1991). Oocytes injected with human substantia nigra mRNA also demonstrate similar sodium-dependent dopamine uptake activity (Bannon et al 1990).

Expression cloning strategies that use oocytes offer a powerful approach to the isolation of genes encoding low abundance membrane proteins. This approach is most useful when the gene product of interest is encoded by a single RNA species. Several sodium cotransporters, including the bacterial $\mathrm{Na}^{+}$/proline (Nakao et al 1987) and the mammalian $\mathrm{Na}^{+} /$glucose (Hediger et al 1987,1989$)$ had previously been shown to contain single subunits. Experimental support for the idea that neurotransmitter transporters are encoded by single RNAs was obtained from oocyte expression studies that demonstrated that discrete size classes of mRNA direct the synthesis of different amino acid neurotransmitter transporters. Sucrose gradient 
fractionation experiments using oocytes also addressed the structural diversity of mRNAs that encode the amino acid neurotransmitter transporters (Blakely et al 1991a). The transporters for glutamate, GABA, and glycine are encoded by different size classes of RNA in different brain regions and, together with pharmacologic data, suggested a greater complexity of carrier subtypes than had been anticipated.

\section{Purification and Cloning of a Brain GABA Transporter}

A rat brain GABA transporter purified to apparent homogeneity (Radian et al 1986; Radian \& Kanner 1986) provided an important reagent for the molecular cloning of a GABA transporter cDNA. Partial protein sequence information from cyanogen bromide fragments generated peptide sequences for oligonucleotide probes that were used to isolate a GABA transporter cDNA by standard plaque hybridization techniques (Guastella et al 1990). When expressed in Xenopus oocytes, this cDNA clone encoded a GABA transporter that was sodium- and chloride-dependent and had the pharmacologic sensitivity of the purified GABA transporter. Hydropathy analysis contributes clues to the structure of the transporter and suggests that the predicted $67 \mathrm{kDa}$ protein contains $11-13$ potential membranespanning domains. The amino-terminus lacks an identifiable signal sequence (von Heijne 1983) and is thus likely to be retained in the cytoplasm. Although several variations can be proposed, the GABA transporter structure is most readily described by a model with 12 transmembrane domains, intracellular amino- and carboxyl-termini, and a large extracellular loop with three glycosylation sites between transmembrane domains 3 and 4. (See Figure 1.)

\section{Expression Cloning of the Norepinephrine Transporter}

A COS cell expression system served as the basis for isolating a clone encoding a human norepinephrine transporter (Pacholczyk et al 1991). The SK-N-SH human neuroblastoma cell line expresses a homogeneous population of sodium-dependent catecholamine transporters with the pharmacologic characteristics of a norepinephrine transporter(Richards \& Sadee 1986). In addition to catecholamines, this carrier can also transport meta-iodobenzylguanidine (mIBG), a compound structurally similar to the neuronal blocking agents guanethidine and bretylium. This analogue can be labeled with $\left[{ }^{125} \mathrm{I}\right]$ and remains stable when accumulated intracellularly. A cDNA library constructed by using RNA from SK-N-SH cells was transfected into COS-l cells; those cells that expressed specific uptake activity were identified by autoradiography by using [ $\left.{ }^{125} \mathrm{I}\right] \mathrm{mIBG}$. Episomal DNA from areas of cells corresponding to autoradiographic spots was rescued by Hirt lysis and transformed into bacteria. This process 
led to a single, purified clone encoding a novel carrier with the substratespecificity and pharmacologic properties, including antidepressant- and cocaine-sensitivity, expected for a norepinephrine transporter.

RNA hybridization studies with the clone confirm the presence of transporter mRNA in tissues and cell lines that synthesize the norepinephrine transporter. Interestingly, both human SK-N-SH and rat PC-1 2 cells contain two RNAs, $3.6 \mathrm{~kb}$ and $5.8 \mathrm{~kb}$ in length, which hybridize at high stringency to probes specific for the norepinephrine transporter cDNA. The $5.8 \mathrm{~kb}$ species has the expected pattern of distribution of the norepinephrine transporter, with highest expression in the adrenal gland and brainstem regions containing the locus coeruleus. The $3.6 \mathrm{~kb}$ RNA, which appears to arise from the same gene, is more diffusely expressed in neural tissues and could, perhaps, encode a norepinephrine carrier in glial cells.

The sequence of the norepinephrine transporter cDNA predicts a protein of 617 amino acids and a molecular weight of approximately 69 $\mathrm{kD}$. The hydrophobicity plot of the norepinephrine sequence is virtually superimposable upon that of the GABA, which suggests similar membrane topographies for the two. The GABA and norepinephrine transporters also show significant primary amino acid sequence identity (46\%), particularly within and adjacent to the putative transmembrane domains (see Figure 2). In fact, in one stretch of conserved residues overlapping transmembrane domains 1 and 2, 17 of 18 residues are identical in the two transporters. Perhaps surprisingly, the two proteins show little sequence similarity with other known ion-coupled cotransporters or neurotransmitter receptors; thus, they define a novel gene family of neurotransmitter cotransport proteins.

\section{Cloning of Dopamine and Serotonin Transporters by Sequence Similarity}

The significant homology between the norepinephrine and GABA transporters became the basis for the isolation of cDNA clones encoding rat (Kilty et al 1991; Shimada et al 1991a) and bovine (Usdin et al 1991) dopamine transporters, as well as a serotonin transporter (Blakely et al 1991a; Hoffman et al 1991). Degenerate oligonucleotides corresponding to regions of high sequence identity between the norepinephrine and GABA transporters served as probes or were the basis of polymerase chain reactions (PCR) to generate probes for screening cDNA libraries. Figure 2 compares the amino acid sequences predicted for the members of this gene family. The high degree of amino acid identity among the norepinephrine, dopamine, and serotonin transporters is not surprising in light of their 
DAT

NET

GAT

5HT-T

BGT1

DAT

NET

GAT

BGT1

DAT

\section{NET}

GAT

SHT-

BGT

DAT

GAT

5HT-T

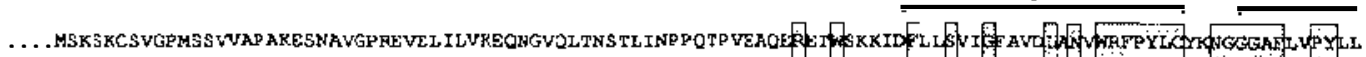

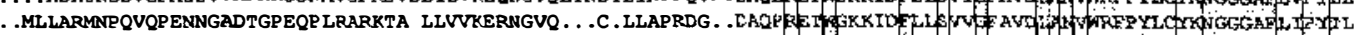

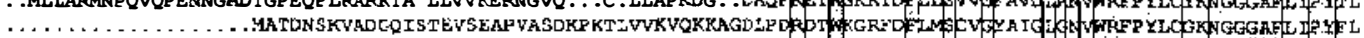

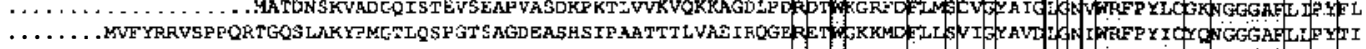

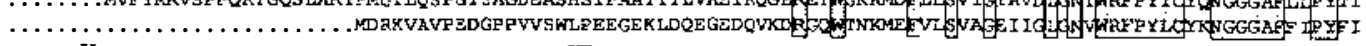
II

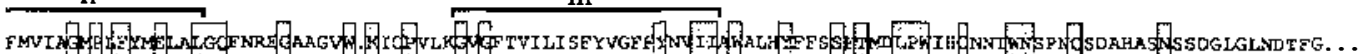

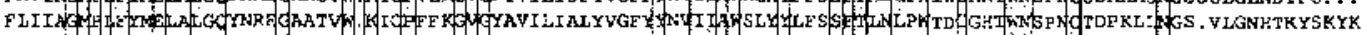

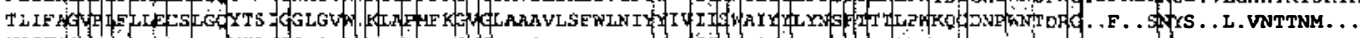
MAIEGSIE IEY FFFTd de

\section{IV} $\mathbf{V}$

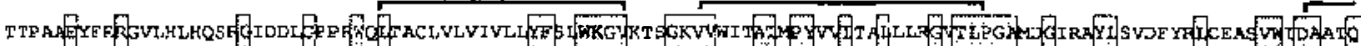

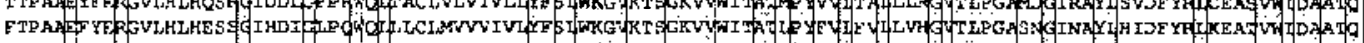

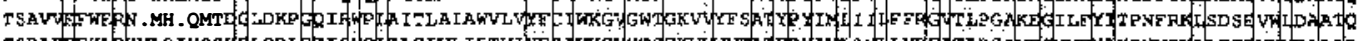

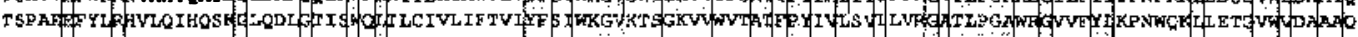

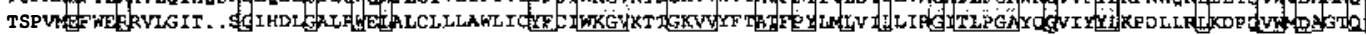
VI VII VIII

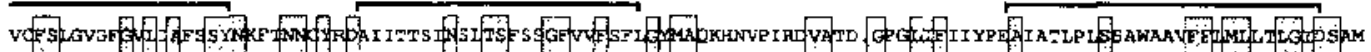

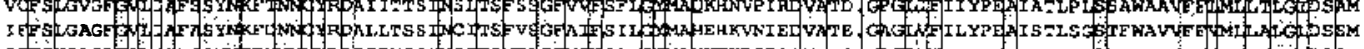

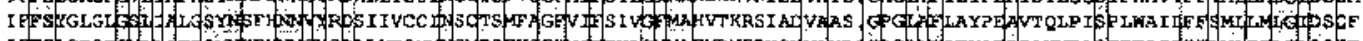

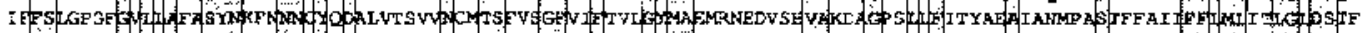

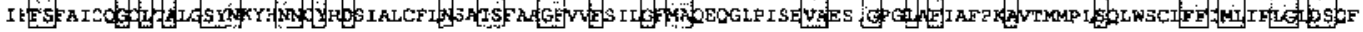

\section{IX} $\mathbf{X}$

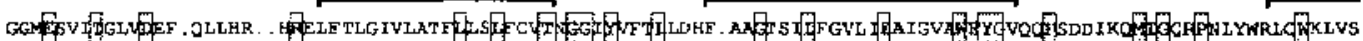

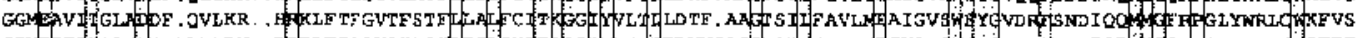

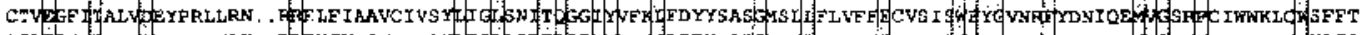

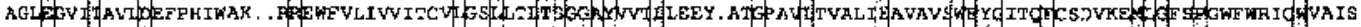

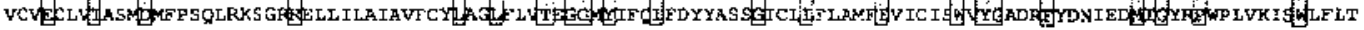
$\mathrm{XI}$ XII

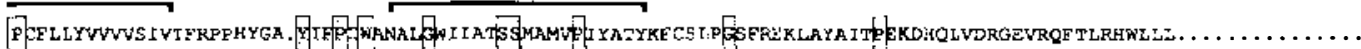

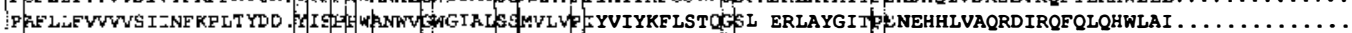

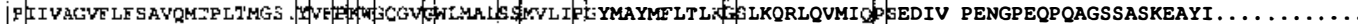
PUFLLCE

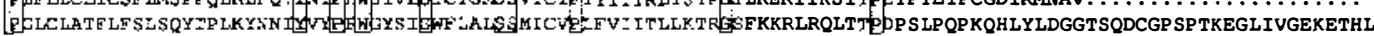

Figure 2 Alignment of the predicted amino acid sequences of the rat dopamine (DAT) (Kilty et al 1991; Shimada et al 1991 a), human norepinephrine (NET) (Pacholczyk et al 1991), rat GABA (GAT) (Guastella et al 1990), rat serotonin 5-HTT (Blakely et al 1991a), and canine betaine (BGT-1) (Yamauchi et al 1992) transporters. Shaded areas represent regions of amino acid identity among all five transporters. The location of 12 potential transmembrane helices are noted. 
overlapping pharmacologic sensitivities. However, several regions appear to be subject to different selective pressures. Among all members of the family, the amino termini, large extracellular loops, and carboxyl-termini show much less sequence similarity than the putative membrane-spanning domains and their immediate boundaries.

In all brain regions and cell lines studied thus far, the dopamine and serotonin transporters appear to be encoded by single $3.6 \mathrm{~kb}$ and $3.7 \mathrm{~kb}$ mRNAs, respectively. However, the existence of minor splicing variants or very closely related genes that alter the sequence of the transporter, but not the overall size or hybridization stringency of the mRNA, cannot be categorically ruled out.

Both transporters displayed an appropriate pharmacology and have been localized to brain pathways specific to each neurotransmitter. In situ hybridization studies that use a cloned dopamine transporter cDNA show intense hybridization in the substantia nigra, with more caudal sections containing an additional region of hybridization corresponding to dopaminergic cell bodies present in the ventral tegmental area (Kilty et al 1991; Shimada et al 1991a). There was also hybridization in the periphery of the olfactory bulb and in discrete regions of the hypothalamus, both sites of dopaminergic cell bodies. Within the rat brain, serotonin transporter RNA was observed within dorsal and medial subdivisions of the midbrain Raphe complex (Blakely et al 1991a).

\section{A Sodium- and Chloride-Dependent Transporter Gene Family}

Additional members of the neurotransmitter transporter gene family have been identified by using PCR primers based on regions of significant amino acid sequence similarity between the norepinephrine and GABA transporters (Clark et al 1991; Peek et al 1991; Shimada et al 1991b). These experiments have generated cDNA probes encoding many novel products with clear structural similaritics to norepinephrine and GABA carriers. The regional distribution of RNAs encoding these putative transporters (Clark et al 1991) suggests that the expression of members of the family is not restricted to the nervous system. Compelling evidence for this idea is provided by the expression cloning in Xenopus oocytes of the transporter for the osmolyte glycine betaine from MDCK cells (Yamauchi et al 1992). This transporter, which is expressed predominantly in the renal medulla, has a predicted amino acid sequence that is remarkably similar to members of the neurotransmitter transporter gene family. This carrier catalyzes the sodium- and chloride-dependent accumulation of betaine and GABA. Table 2 summarizes some of the basic structural and pharmacologic properties of currently characterized members of this gene family. 
Table 2 Properties of cloned transporters

\begin{tabular}{|c|c|c|c|c|c|c|c|}
\hline Transporter & rat GABA & $\begin{array}{c}\text { hum } \\
\text { GABA }^{n}\end{array}$ & hum $\mathrm{NE}^{\mathrm{c}}$ & rat $\mathrm{DA}^{\mathrm{d}}$ & bov $\mathrm{DA}^{\mathrm{e}}$ & rat $5-\mathrm{HT}^{\mathrm{i}}$ & dog betaine ${ }^{g}$ \\
\hline Amino acids & 599 aа & 599 aa & 617 aa & 619 aa & 693 aa & 607,653 aa & 614 aa \\
\hline Relative molecular mass & $67 \mathrm{kD}$ & $67 \mathrm{kD}$ & $69 \mathrm{kD}$ & $69 \mathrm{kD}$ & $77 \mathrm{kD}$ & $69,73 \mathrm{kD}$ & $69 \mathrm{kD}$ \\
\hline Glycosylation sites ${ }^{\mathrm{h}}$ & 3 & 3 & 3 & 4 & 3 & 2 & 2 \\
\hline Phosphorylation sites $^{h}$ & yes & yes & yes & yes & yes & yes & yes \\
\hline Substrates & GABA & GABA & $\mathrm{NE}, \mathrm{DA}$ & DA & DA & $5-\mathrm{HT}$ & betaine, GABA \\
\hline $\mathrm{Na}^{+}$and $\mathrm{Cl}^{-}$dependent & yes & n.d. & yes & yes & yes & yes & yes \\
\hline Selective inhibitors & $\begin{array}{l}\mathrm{ACHC}, \\
2,4-\mathrm{DABA}\end{array}$ & n.d. & desipramine & GBR 12909 & GBR12909 & paroxetine & \\
\hline Other inhibitors & nipecotic acid & n.d. & $\begin{array}{l}\text { cocaine, } \\
\text { amphetamines, } \\
\text { tricyclic } \\
\text { antidepressants }\end{array}$ & $\begin{array}{l}\text { cocaine, } \\
\text { amphetamines }\end{array}$ & $\begin{array}{l}\text { cocaine, } \\
\text { amphetamines }\end{array}$ & $\begin{array}{l}\text { cocaine } \\
\text { amphetamines, } \\
\text { tricyclic } \\
\text { antidepressants }\end{array}$ & $\begin{array}{l}\text { quinidine, } \\
\text { phloretin, } \\
\text { beta-alanine }\end{array}$ \\
\hline RNA size & $4.2 \mathrm{~kb}$ & $4.4 \mathrm{~kb}$ & $3.6,5.8 \mathrm{~kb}$ & $3.6 \mathrm{~kb}$ & $3.0 \mathrm{~kb}$ & $3.7 \mathrm{~kb}$ & $2.4,3.0 \mathrm{~kb}$ \\
\hline Tissue distribution & brain & brain & $\begin{array}{l}\text { locus coeruleus, } \\
\text { adrenal, } \\
\text { PCI } 2 \text { cells, } \\
\text { SKNSH cells }\end{array}$ & $\begin{array}{l}\text { SN, VTA, } \\
\text { hypothalamus, } \\
\text { olfactory bulb }\end{array}$ & $\begin{array}{l}\text { SN, VTA, } \\
\text { hypothalamus, } \\
\text { olfactory bulb }\end{array}$ & $\begin{array}{l}\text { Raphe nuclei, } \\
\text { lung, adrenal, } \\
\text { RBL cells }\end{array}$ & $\begin{array}{l}\text { kidney, } \\
\text { MDCK cells }\end{array}$ \\
\hline
\end{tabular}

"Guastella et al 1990 .

${ }^{\mathrm{b}}$ Nelson et al 1990.

'Pacholczyk et al 1991

¿Kilty et al 1991; Shimada et al 1991

'Usdin et al 1991. The carboxyl terminus of the bovine dopamine transporter diverges and is much longer than the three reported rat sequences for catecholamine transporters. This may be the result of a base change or sequencing error that shifts the reading frame.

'Blakely et al 1991: Hoffman et al 1991. The two reported rat serotonin transporter cDNAs have isolated base differences that cause the protein sequences to diverge at their carboxyl termini. Their amino-termini diverge completely. Whether these reflect actual differences or cloning artifacts remains to be determined.

Yamauchi et al 1992.

${ }^{\text {h }}$ Predicted from consensus sequences apparent within the primary amino acid sequence. 


\section{Common Structural Motifs}

The striking similarities in the sequences of the cloned ncurotransmitter carriers begin to define the structural features common to this transporter gene family (Figure 2). Conserved features may point to the structural elements important in generic functions, such as sodium and chloride cotransport. Regions of divergence may suggest potential determinants of specificity for each transporter, including substrate and inhibitor binding sites. Mutagenesis studies should prove useful in defining these regions. A few aspects of the predicted structures are worth discussing.

Although the neurotransmitter transporters have no significant sequence homology with other families of carriers, the presence of 11-13 transmembrane domains appears to be a recurrent theme among both bacterial and mammalian symporters (Hediger et al 1987; Kaback 1988; Nakao et al 1987). In the neurotransmitter carrier family, transmembrane domains 1,2 and 4-8 show the highest degree of sequence identity. The conservation of sequence in these membrane-spanning regions argues for their functional importance in transport activity, but details of their function is not yet known. Sequence identity is most pronounced at points where the polypeptide would be expected to enter or exit the membrane. This degree of conservation may reflect the importance of these residues in determining the folding pattern and orientation of helices within the membrane.

Four leucine residues arranged in a pattern resembling a leucine zipper are present in transmembrane domain 2 in norcpinephrine and GABA (Pacholczyk et al 1991), but are less well conserved in the other cloned transporters. Such motifs could be the basis for dimerization of subunits or interactions with other membrane-spanning domains. Although a single gene product suffices to reconstitute transport activity in mammalian expression systems, data do not distinguish whether any of these transporters are functionally active as monomers [as suggested for the lac permease protein (Costello et al 1987)], as homomultimeric complexes [as suggested for the $\mathrm{Na}^{+}$/glucose transporter protein (Stevens et al 1990)], or as heteromultimeric complexes. Interestingly, radiation inactivation studies on the dopamine transporter predict a size for the carrier complex that is significantly larger than the cloned transporter protein and may suggest the presence of additional modulatory subunits (Berger et al 1991).

Several discrete charged and polar residues within otherwise hydrophobic transmembrane domains are conserved between the transporters (e.g. glutamate residues in transmembrane domains 2 and 10), and at least one charged residue is unique to the monoamine carriers. For the $G$ protein coupled receptors, ligand-binding domains appear to reside in 
multiple regions largely within the hydrophobic core of the proteins. Residues implicated as part of ligand-binding domains in adrenergic receptors have been examined in site-directed mutagenesis studies, which suggest that a conserved aspartate residue in transmembrane domain 3 is critical for the binding of both agonists and antagonists with protonated amine groups (Horstman et al 1990; Strader et al 1987). By analogy, specific residues common to the catecholamine transporters, but absent in the GABA transporter, could combine to form a three-dimensional catecholamine binding site. The aspartate residue in transmembrane domain 1 (Asp 79 in the dopamine transporter) is conserved in dopamine, norepinephrine, and serotonin transporters, but is substituted by a glycine in the GABA and betaine transporters, which suggests that this residue may be selectively important for monoamine transporter function. In support of this idea, studies on the structure activity relationships of tricyclic antidepressants have led to the proposal that these agents, like norepinephrine, form bonds from a terminal ammonium group to a negatively charged residue in the norepinephrine transporter (DePaulis et al 1978; Maxwell et al 1969).

Serine residues have been proposed in the adrenergic receptors to act as a hydrogen bond donor for interactions with the catechol groups of catecholamines. Putative transmembrane domain 7, although hydrophobic in character, has a very different character with a high percentage of serine, threonine, and cysteine residues throughout the segment. In the dopamine transporter transmembrane, domains 6 and 8 also have several serine and threonine residues. Thus, this portion of the transporter could also be functionally significant in the transport of the catechol moiety of the catecholamines.

Charged residues are frequently positioned at the boundaries between hydrophilic loops and putative membranc-embedded domains. An analysis by von Heijne (1986) revealed that integral membrane proteins frequently have charged residues bordering on hydrophobic regions and that these residues may play a role in determining the correct positioning of the protein within the membrane. Focal clusters of 4-5 charged residues in the cytoplasmic loop immediately preceding transmembrane helix 9 are found in all cloned neurotransmitter transporters. Similar clusters of charged residues are evident in analogous locations in the bacterial $\mathrm{Na}^{+}$/proline and mammalian $\mathrm{Na}^{+}$/glucose transport proteins (Hediger et al 1989).

Membrane-buried proline residues serve an important role in transport proteins. A survey of integral membrane protein sequences (Brandl \& Deber 1986) provides evidence that, although proline residues are largely cxcluded from membrane-spanning segments in nontransport proteins, 
they are evenly distributed between aqueous and membrane domains in transport proteins. Prolines have been suggested to have three potential roles within membrane-spanning helices. Local structural changes arising from regulated cis-trans isomerization of membrane-buried X-proline peptide bonds $(\mathrm{X}=$ unspecified amino acid) of transport proteins could result in the realignment of amphipathic helices to provide the conformational changes required for substrate translocation, such that a hydrophilic pore becomes accessible to a substrate ready for transport across the membrane (Brandl \& Deber 1986). Prolines also introduce a bend in transmembrane helices, possibly allowing the formation of a pocket that could accommodate substrates or ligands. Finally, the more negative character of carbonyl groups of $\mathrm{X}$-proline peptide bonds make them more likely to participate in hydrogen bonding or interact with cations within the membrane. The neurotransmitter transporter family has conserved proline residues in 5 of $12(1,2,5,11,12)$ transmembrane domains.

The large putative extracellular loop between transmembrane domains 3 and 4 in both transporters has three predicted $\mathrm{N}$-glycosylation sites, but otherwise has little sequence homology. The significance of the oligosaccharides to transport, ligand-binding, or protein targeting has not yet been explored. However, a study in which neuraminidase treatment of synaptosomes resulted in a $40 \%$ decrease in Vmax of dopamine transport (Zalecka \& Erecinska 1987) suggests that carbohydrate moieties may serve an important role in transporter function. The presence of multiple (2-4) $\mathrm{N}$-linked sites in the different transporters also raises the possibility that variations in glycosylation patterns could contribute to transporter heterogeneity. Biochemical studies support this idea. The apparent molecular weight of the dopamine transporter from rat nucleus accumbens is higher than that in the striatum (Lew et al 1991b), but after deglycosylation of the transporters from the two regions, the difference in apparent molecular weight is negligible (Lew et al 1992).

Although the large extracellular loop is less well conserved in the neurotransmitter transporters, two cysteines, 9 residues apart, are common to all members of the family. Dixon et al (1987) and Fraser (1989) have addressed the role of conserved cysteine residues in adrenergic receptor function. Site-directed mutagenesis of two cysteine residues within different extracellular loops of the $\beta$-2 adrenergic receptor (residues 106 and 184) characteristically alters the ligand-binding properties (Dixon et al 1987) and has led to the proposal that these conserved cysteine residues form a disulfide-linked pair. Similarly, the cysteine residues that are highly conserved within neurotransmitter transporters could form disulfide bonds and impart tertiary structure to the extracellular loop.

It is tempting to assign the regions of sequence homology common to 
all the transporters to functions involved in the transport of sodium. A putative "sodium-binding" domain has been proposed for a bacterial $\mathrm{Na}^{+}$/glutamate transporter, based on a short, loosely defined region of amino acid sequence similarity present in several sodium symporters (Deguchi et al 1990). This sequence motif is not present in the neurotransmitter transporter family. However, such common motifs might not be expected, because although all the neurotransmitter transporters cotransport sodium, the stoichiometry of sodium to transmitter, the codependence on extracellular chloride, and the role of intracellular $\mathrm{K}$ differ between the various members of the family, and from other symporters, as well.

\section{Regulation of Neurotransmitter Transport}

The presence of serine and threonine residues that could be substrates for phosphorylation in the cytoplasmic amino- and/or carboxyl-termini of the neurotransmitter transporters cloned to date (Blakely et al 1991a; Guastella et al 1990; Hoffman et al 1991; Kilty et al 1991; Nelson et al 1990; Pacholczyk et al 1991; Shimada et al 1991a; Usdin et al 1991; Yamauchi et al 1992) supports the hypothesis that second messengcrs may dynamically regulate the function of these transporters. In the nervous system, membrane depolarization and second messengers, such as calcium and arachidonic acid, modulate activity or expression of choline (Boksa et al 1988; Murrin \& Kuhar 1976; Saltarelli et al 1988, 1990; Simon et al 1976) and glutamate (Barbour et al 1989; Murrin et al 1978; Yu et al 1986) transport, which suggests that synaptic activity itself may influence neurotransmitter reuptake. Studies of primary astrocytes have indicated that activation of $\beta$-adrenergic receptors (Hansson \& Ronnback 1989) or protein kinase $C$ (Gomeza et al 1991) may regulate glial GABA transport. Additional studies support a role for second messenger pathways in modulating monoamine uptake activities. Both serotonin transport in a choriocarcinoma cell line (JAR cells) (Cool et al 1991) and dopamine transport in primary hypothalamic cells (Kadowaki et al 1990) are stimulated by cAMP. Inhibitors of arachidonic acid metabolism are relatively potent dopamine uptake blockers in rat striatal slices (Cass et al 1991), which suggests that arachidonic acid metabolites may be important for the regulation of dopamine transport activity.

There are likely to be other mechanisms that regulate the activities of neurotransmitter transporters. These include the direct influence of transmembrane electrochemical gradients that determine the driving force for transport, and in some instances, when altered, can lead to reversed transport. In addition, some reports have suggested that an important mechanism for regulating transport activity of facilitated glucose transporters is the subcellular redistribution of transporters from cryptic intra- 
cellular pools to the plasma membrane (reviewed in Simpson \& Cushman 1986). For neurotransmitter transporters, such a mechanism could contribute to observed instances of regulated changes in the Vmax of transport. Developmental and trans-synaptic events are also likely to control the expression of brain transporter genes and lead to changes in transporter mRNA abundance (for example, Blakely et al 1991b). The availability of cloned probes should now make gene expression studies more feasible.

\section{CONCLUSIONS}

Although much emphasis has been placed on the molecular biology of proteins, such as ion channels and receptors that mediate synaptic signaling, less attention has been directed at the gene products important for the process of signal termination. Recent progress in molecular cloning and the elucidation of carrier structure establishes a new gene family encoding $\mathrm{Na}^{+}$-dependent neurotransmitter transporters. The availability of new tools for studying reuptake processes at the molecular level should enable rapid progress in the field.

\section{Literature Cited}

Amara, S. G., Pacholczyk, T. 1991. Sodiumdependent neurotransmitter reuptake systems. Curr. Opin. Neurobiol. 1: 84-90

Axelrod, J., Weil-Malherbe, H., Tomchick, R. 1959. The physiological disposition of $\mathrm{H}^{3}$-epinephrine and its metabolite metanephrine. J. Pharmacol. Exp. Ther. 127: $251-56$

Bannon, M. J., Zue, C. H., Shibata, K., Dra* govic, L. J., Kapatos, G. 1990. Expression of a human cocaine-sensitive dopamine transporter in Xenopus laevis oocytes. J. Neurochem. 54: 706-8

Barbour, B., Szatkowski, M., Ingledew, N., Attwell, D. 1989. Arachidonic acid induces a prolonged inhibition of glutamate uptake into glial cells. Nature 342 : 918-20

Berger, P., Kempner, E. S., Paul, S. M. 1991. Radiation inactivation studies of the dopamine transporter protein. Soc. Neurosci. Abstr. 17: 190

Berger, P., Martenson, R., Laing, P., Thurcauf, A., DeCosta, B., et al. 1990. Photoaffinity labeling of the dopamine reuptake carrier protein using a novel high affinity ayidoderivative of GBR-12935. Soc. Neurosci. Abstr. 16: 13

Bergman, J., Madras, B. K., Johnson, S. E., Spealman, R. D. 1989. Effects of cocaine and related drugs in nonhuman primates
III. Self-administration by squirrel monkeys. J. Pharmacol. Exp. Ther. 251: 15055

Biessen, E. A., Horn, A. S., Robillard, G. T. 1990. Partial purification of the 5 hydroxy tryptophan reuptake system from human blood platelets using a citalopramderived affinity resin. Biochemistry 29: 3349-54

Blakely, R. D., Berson, H. E., Fremeau, R. T., Caron, M. G., Peek, M. M., et al. 1991a. Cloning and expression of a functional serotonin transporter from rat brain. Nature 354: 66-70

Blakely, R. D., Clark, J. A., Pacholczyk, T., Amara, S. G. 1991b. Distinct, developmentally regulated brain and mRNAs direct the synthesis of neurotransmitter transporters. J. Neurochem. 56: 860-71

Blakely, R. D., Robinson, M. B., Amara, S. G. 1988. Expression of neurotransmitter transpot from rat brain mR NA in Xenopus laevis oocytes. Proc. Natl. Acad. Sci. USA 85: 9846-50

Boksa, P., Mykitta, S., Collier, B. 1988. Arachidonic acid inhibits choline uptake and depletes acetylcholine content in rat cerebral cortical synaptosomes. J. Neurochem. 50: 1309-18

Bowery, N. G., Jones, G. P., Neal, M. J. 1976. Selective inhibition of neuronal 
GABA uptake by cis-1,3-aminocyclohexane carboxylic acid. Nature 264: 28184

Brandl, C. J., Deber, C. M. 1986. Hypothesis about the function of membrane-buried proline residues in transport proteins. Proc. Natl. Acad. Sci.US A 83: 917-21

Brown, G. L., Gillespie, J. S. 1957. The output of sympathetic transmitter from the spleen of the cat. J. Physiol. 138: 81-102

Burn, J. H. 1932. The action of tyramine and ephedrine. J. Pharmacol. Exp. Ther. 46: 75-95

Cass, W. A., Larson, G., Fitzpatrick, F. A., Zahniser, N. R. 1991. Inhibitors of arachidonic acid metabolism: effects on rat striatal dopamine release and uptake. J. Pharmacol. Exp. Ther. 257: 990-96

Clark, J. A., Fluet, A. A., Amara, S. G. 1991. Isolation of new members of a transporter gene family by sequence homology-based PCR. Soc. Neurosci. Abstr. 17: 1183

Cool, D. R., Leibach, F. H., Bhalla, V. K., Mahesh, V. B., Ganapathy, V. 1991. Expression and cAMP regulation of a high affinity serotonin transporter in human placental choriocarcinoma cell line (JAR). J. Biol. Chem. 266: 15750-57

Costello, M. J., Escaig, J., Matsushita, K., Viitanen, P. V., Menick, D. R., Kaback, H. R. 1987. Purified lac permease and cytochrome o oxidase are functional as monomers. J. Biol. Chem. 262: 17072-82

Cummins, C. J., Glover, R. A., Sellinger, O. Z. 1982. Beta-alanine is not a marker for brain astroglia in culture. Brain Res. 239: 299-302

Dcguchi, Y., Yamato, I., Anraku, Y. 1990. Nucleotide sequence of $g l t \mathrm{~S}$, the $\mathrm{Na}^{+} / \mathrm{glu}-$ tamate symport carrier gene of Escherichia coli B*. J. Biol. Chem. 265: 21704-8

DePaulis, T., Kelder, D., Ross, S. B. 1978. On the topology of the norepinephrine transport carrier in rat hypothalamus: the site of action of tricyclic uptake inhihitors. Mol. Pharmacol. 14: 596-606

Dixon, R. A. F., Sigal, I. S., Candelore, M. R., Register, R. B., Scattergood, W., et al. 1987. Structural features required for ligand binding to the $\beta$-adrenergic receptor. EMBO J. 6: 3269-75

Fraser, C. M. 1989. Site-directed mutagenesis of $\beta$-adrenergic receptors. J. Biol. Chem. 264: 9266-70

Fuller, R. W., Wong, D. T. 1990. Ann. NY Acad. Sci. 600: 68-80

Gomeza, J., Casado, M., Gimenez, C., Aragon, C. 1991. Inhibition of highaffinity $\gamma$-aminobutyric acid uptake in primary astrocyte cultures by phorbol cstcrs and phospholipase C. Biochem. J. 275: 435-39

Gordon, A. M., Kanner, B. I. 1988. Partial purification of the sodium- and potassium-coupled L-glutamate transport glycoprotein from rat brain. Biochim. Biophys. Acta 944: 90--96

Graham, D., Esnaud, H., Langer, S. Z. 1991. Characterization and purification of the neuronal sodium-ion-coupled 5-hydroxytryptamine transporter. Biochem. Soc. Trans. 19: 99-102

Grigoriadis, D. E., Wilson, A. A., Lew, R., Sharkey, J. S., Kuhar, M. J. 1989. Dopamine transport sites selectively labeled by a novel photoaffinity probe: ${ }^{125}$ I-DEEP. J. Neurosci. 9: 2664-70

Guastella, J., Nelson, N., Nelson, H., Czyzk, L., Keynan, S., et al. 1990. Cloning and expression of a rat brain GABA transporter. Science 249: 1303-6

Hansson, E., Ronnback, L. 1989. Regulation of glutamate and GABA transport by adrenoceptors in primary astroglial cell cultures. Life Sci. 44: 27-34

Hediger, M. A., Coady, M. J., Ikeda, T. S., Wright, E. M. 1987. Expression cloning and cDNA sequencing of the $\mathrm{Na}^{+} /$glucose cotransporter. Nature 330: 379-81

Hediger, M. A., Turk, E., Wright, E. M. 1989. Homology of the human intestinal $\mathrm{Na}^{+}$/glucose and Escherichia coli $\mathrm{Na}^{+} /$ proline cotransporters. Proc. Natl. Acad. Sci. USA 86: 5748-52

Hoffman, B. J., Mezby, E., Brownstein, M. J. 1991. Cloning of a serotonin transporter afrected by antidepressants. Science 254: 79-80

Horn, A. S. 1990. Dopamine uptake: A review of progress in the last decade. Prog. Neurobiol. 34: 387--400

Horstman, D. A., Brandon, S., Wilson, A. L., Guyer, C. A., Cragoe, E. J., Limbird, L. E. 1990. An aspartateconserved among G-protein receptors confers allosteric regulation of a2-adrenergic receptors by sodium. J. Biol. Chem. 265: 21590-95

Iversen, L. L. 1975. Uptake process of biogenic amines. In Handbook of Psychopharmacology, ed. L. L. Iversen, S. D. Iversen, S. H. Snyder, pp. 381-442. New York: Plenum

Iversen, L. L. 1967. The Uptake and Storage of Noradrenaline in Sympathetic Nerves. London: Cambridge Univ. Press

Iversen, L. L., Glowinski, J., Axelrod, J. 1966. The physiological disposition and metabolism of norepinephrine in immunosympathectomized animals. J. Pharmacol. Exp. Ther. 151: 273-84

Iversen, L. L., Kelly, J. A. 1975. Uptake and metabolism of $\gamma$-aminobutyric acid by neurones and glial cells. Biochem. Pharmacol. 24: 933-38

Johnstone, R. 1990. Ion-coupled cotransport. Curr. Opin. Cell. Biol. 2: 735-41 
Kaback, H. R. 1988. Site-directed mutagenesis and ion-gradient driven active transport: on the path of the proton. Annu. Rev. Physiol. 50: 243-56

Kadowaki, K., Hirota, K., Koike, K., Ohmichi, M., Kiyama, H., et al. 1990. Adenosine $3^{\prime}, 5^{\prime}$-cyclic monophosphate enhances dopamine accumulation in rat hypothalamic cell culture containing dopaminergic neurons. Neuroendocrinology 52: 256-61

Kanner, B. I., Keynan, S., Radian, R. 1989. Structural and functional studies on the sodium- and chloride-coupled $\gamma$-aminobutyric acid transporter: deglycosylation and limited proteolysis. Biochemistry 28: 3722-28

Kanner, B. I., Schuldiner, S. 1987. Mechanism of transport and storage of ncurotransmitters. CRC Crit. Rev. Biochem. 22: $1-38$

Keynan, S., Kanner, B. I. 1988. $\gamma$-aminobutyric acid transport in reconstituted preparations from rat brain: coupled sodium and chloride fluxes. Biochemistry 27: $12-17$

Kilty, J. E., Lorang, D., Amara, S. G. 1991. Cloning and expression of a cocaine-sensitive rat dopamine transporter. Science 254: 578-79

Kimelberg, H. K., Katz, D. M. 1986. Regional differences in 5-hydroxytryptamine and catecholamine uptake in primary astrocytic cultures. J. Neurochem. 47: 1647-52

Kimelberg, H. K., Katz, D. M. 1985. High affinity uptake of serotonin into immunocytochemically identified astrocytes. Science 228: 889-95

Kimelberg, II. K., Pelton, E. W. 1983. Highaffinity uptake of $[3 \mathrm{H}]$ norcpinephrine by primary astrocyte cultures and its inhibition by tricyclic antidepressants. $J$. Neurochem. 40: 1265-70

Kuhar, M. J. 1973. Neurotransmitter uptake: A tool for identifying neurotransmitter-specific pathways. Life Sci. 33: 1623 34

Kuhar, M. J., Murrin, L. C. 1978. Sodiumdependent, high affinity choline uptake. $J$. Neurochem. 30: 15-21

Kuhar, M. J., Ritz, M. C., Boja, J. W. 1991. The dopamine hypothesis of the reinforcing properties of cocaine. Trends Neurosci. 14: 299-302

Kuhar, M. J., Zarbin, M. A. 1978. Synaptosomal transport: a chloride dependence for choline, GABA, glycine, and several other compounds. J. Neurochem. 31:25156

Langer, S. Z., Briley, M. 1981. High affinity ${ }^{3} \mathrm{H}$-imipramine binding: a new biological tool for studies in depression. Trends
Neurosci. 4: 28-31

Langer, S. Z., Raisman, R. 1983. Binding of $\left[{ }^{3} \mathrm{H}\right]$ imipramine and $\left[{ }^{3} \mathrm{H}\right]$ desipramine as biochemical tools for studies in depression. Neuropharmacology 22: 407-13

Larsson, O. M., Griffiths, R., Allen, I. C., Schousboe, A. 1986. Mutual inhibition kinetic analysis of $\gamma$-aminobutyric acid, taurine, and $\beta$-alanine high-affinity transport into neurons and astrocytes: evidence for similarity between taurine and $\beta$-alanine carriers in both cell types. J. Neurochem. 47: 426-32

Lew, R., Grigoriadis, D. E., Wilson, A., Boja, J. W., Simantov, R., Kuhar, M. J. 199la. Dopamine transporter: deglycosylation with exo- and endoglycosidascs. Brain Res. 539: 239-46

Lew, R., Patel, A., Vaughn, R. A., Wilson, A., Kuhar, M. J. 1992. Microheterogeneity of dopamine transporters in rat striatum and nucleus accumbens. Brain Res. 584: 266-71

Lew, R., Vaughn, R., Simantov, R., Wilson, A., Kuhar, M. J. 1991b. Dopamine transporters in the nucleus accumbens and the striatum have different apparent molecular weights. Synapse 8: 152-53

Lopez-Corcuera, B., Kanner, B. I., Aragon, C. 1989. Reconstitution and partial purification of the sodium and chloridecoupled glycine transporter from rat spinal cord. Biochim. Biophys. Acta 983: 247-52

Malchow, R. P., Ripps, H. 1990. Effects of gamma-aminobutyric acid on skate retinal horizontal cells: evidence for an electrogenic uptake mechanism. Proc. Natl. Acad. Sci. USA 87: 8945-49

Maxwell, R. A., Keenan, P. D., Chaplin, E., Roth, B., Eckhardt, S. B. 1969. Molccular features affecting the potency of tricyclic antidepressants and structurally-related compounds as inhibitors of the uptake of tritiated norepinephrine by rabbit aortic strips. J. Pharmacol. Exp. Ther. 166: 32029

Murrin, L. C., Kuhar, M. J. 1976. Activation of high affinity choline uptake in vitro by depolarizing agents. Mol. Pharmacol. 12: 1082-90

Murrin, L. C., Lewis, M. S., Kuhar, M. J. 1978. Amino acid transport: alterations due to synaptosomal depolarization. Life Sci. 22: 2009-16

Nakao, T., Yamato, I., Anraku, Y. 1987. Nucleotide sequence of put $P$, the proline carrier gene of Escherichia coli K 12. MGG 208: 70-75

Nelson, H., Mandiyan, S., Nelson, N. 1990. Cloning of the human brain GABA transporter. FEBS Lett. 269: 181-84

Nicholls, D., Attwell, D. 1990. The release 
and uptake of excitatory amino acids. Trends Pharmacol. Sci. 11: 462-68

Pacholczyk, T., Blakely, R. D., Amara, S. G. 1991. Expression cloning of a cocaineand antidepressant-sensitive human noradrenaline transporter. Nature 350: 350 53

Paul, S. M., Rehavi, M., Skolnick, P., Ballenger, J. C., Goodwin, F. K. 1981. Depressed patients have decreased binding of ${ }^{3} \mathrm{H}$-imipramine to the platelets serotonin "transporter." Arch. Gen. Psychiatry 38: 1315-17

Peek, M. M., Fremeau, R. T., Caron, M G., Blakely, R. D. 1991. Identification of multiple members of the neurotransmitter transporter genc family. Soc. Neurosci. Abstr. 17: 904

Pin, J.-P., Bockaert, J. 1989. Two distinct mechanisms, differentially affected by excitatory amino acids, trigger GABA release from fetal mouse striatal neurons in primary culture. J. Neurosci. 9: 648-56

Radian, R., Bendahan, $\Lambda$., Kanner, B. I. 1986. Purification and identification of the functional sodium- and chloride-coupled $\gamma$-aminobutyric acid transport glycoprotein from rat brain. J. Biol. Chem. 261: 15437-41

Radian, R., Kanner, B. I. 1986. Reconstitution and purification of the sodiumand chloride-coupled $\gamma$-aminobutyric acid transport glycoprotcin from rat brain. $J$. Biol. Chem. 260: 11859-65

Radian, R., Ottersen, O. P., StormMathisen, J., Castel, M., Kanner, B. I. 1990. Immunocytochemical localization of the GABA transporter in rat brain. $J$. Neurosci. 10: 1319-30

Rehavi, M., Skolnick, P., Brownstein, M. J., Paul, S. M. 1982. High affinity binding of [ $\left.{ }^{3} \mathrm{H}\right]$ desipramine to rat brain: A presynaptic marker for noradrenergic uptake sites. J. Neurochem. 38: 889-95

Richards, M. L., Sadee, W. 1986. Human neuroblastoma cell lines as models of catechol uptake. Brain Res. 384: 132-37

Ritz, M. C., Lamb, R. J., Goldberg, S. R., Kuhar, M. J. 1987. Cocaine receptors on dopamine transporters are related to selfadministration of cocaine. Science 237: 1219-23

Roberts, P. J., Watkins, J. C. 1975. Structural requirements for the inhibition of $\mathrm{L}$ glutamate uptake by glia and nerve endings. Brain Res. 85: 120-25

Rudnick, G. 1986. ATP-driven $\mathrm{H}^{+}$pumping into intracellular organelles. Annu. Rev. Physiol. 48: 403

Sallee, F. R., Fogel, E. L., Schwartz, E., Choi, S. M., Curran, D. P., Niznik, H. B. 1989. Photoaffinity labeling of the mammalian dopamine transporter. FEBS Lett.
256: 219-24

Saltarelli, M. D., Lopez, J., Lowenstein, P. R., Coyle, J. T. 1988. The role of calcium in the regulation of $\left[{ }^{3} \mathrm{H}\right] \mathrm{Hemicholinium-3}$ binding sites in rat brain. Neuropharmacology 27: 1301-8

Saltarelli, M. D., Yamada, K., Coyle, J. T. 1990. Phospholipase- $\mathrm{A}_{2}$ and ${ }^{3} \mathrm{H}-\mathrm{Hcmi}-$ cholinium-3 binding site in rat brain: a potential second messenger role for fatty acids in the regulation of highaffinity choline uptake. J. Neurosci. 10 : 62-72

Sarthy, V. 1986. $\gamma$-aminobutyric acid (GABA) uptake by Xenopus oocytes in jected with rat brain mRNA. Mol. Brain Res. 1: 97-100

Schwartz, E. 1987. Depolarization without calcium can release GABA from a retinal neuron. Science 238: 350-55

Schwartz, E. 1982. Calcium-independent release of GABA from isolated horizontal cells of the toad retina. J. Physiol. 323: 211-27

Schwartz, E., Tachibana, M. 1990. Electrophysiology of glutamate and sodium cotransport in a glial cell of the salamander retina. J. Physiol. 426: 43-80

Sjöqvist, F., Taylor, P. W. Jr., Titus, E. 1967. The effects of immunosympathectomy on the retention and metabolism of noradrenaline. Acta Physiol. Scand. 69: 13-22

Shimada, S., Kitayama, S., Lin, C.-L., Patel, A., Nanthakumar, E., et al. 1991a. Cloning and expression of a cocaine-sensitive dopamine transporter complementary DNA. Science 254: 576-78

Shimada, S., Kitayama, S., Lin, C.-L., Patel, A., Nanthakumar, E., et al. 199lb. Diversity of neurotransmitter transporter cDNAs in brain libraries. Soc. Neurosci. Abstr. 17: 1182

Shouffani, A., Kanner, B. I. 1990. Cholesterol is required for the reconstitution of the sodium-coupled and chloride-coupled gamma-aminobutyric acid transporter from rat brain. J. Biol. Chem. 265: 6002 8

Simon, J. R., Atweh, S., Kuhar, M. J. 1976. Sodium-dependent high affinity choline uptake: a regulatory step in the synthesis of acetylcholine. J. Neurochem. 26: 90922

Simpson, I. A., Cushman, S. W. 1986. Hormonal regulation of mammalian glucose transport. Annu. Rev. Biochem. 55: 1059 89

Snyder, S. H. 1970. Putative neurotransmitter in the brain: selective neuronal uptake, subcellular localization and interactions with centrally acting drugs. Biol. Psychiatry 2: 367-89

Spealman, R. D., Madras, B. K., Bergman, 
J. 1989. Effects of cocaine and related drugs in nonhuman primates. II. Stimulant effects on schedule-controlled behavior. J. Pharmacol. Exp. Ther. 261: 14249

Stevens, B. R., Fernandez, A., Hirayama, B., Wright, E. M., Kempner, E. S. 1990. Intestinal brush border membrane $\mathrm{Na}+1$ glucose cotransporter functions in situ as a homotetramer. Proc. Natl. Acad. Sci. USA 87: 1456-60

Strader, C. D., Sigal, I. S., Register, R. B., Candelore, M. R., Rands, E., Dixon, R. A. F. 1987. Identification of residues required for ligand binding to the $\beta$-adrenergic receptor. Proc. Natl. Acad. Sci. USA 84: 4384-88

Szatkowski, M., Barbour, B., Attwcll, D. 1990. Non-vesicular release of glutamate from glial cells by reversed electrogenic glutamate uptake. Nature 348: 443-45

Trendelenburg, U. 1991. The TIPS lecture: Functional aspects of the neuronal uptake of noradrenaline. Trends Pharmacol. Sci. 12: $334-37$

Uhl, G. R., O'Hara, B., Shimada, S., Zaczek, R., DiGiorgianni, J., Nishimori, T. 1991. Dopamine transporter: expression in Xenopus oocytes. Mol. Brain Res. 9: 23-29

Usdin, T. B., Mezey, E., Chen, C., Brownstein, M. J., Hoffman, B. J. 1991. Cloning of the cocaine-sensitive bovine dopamine transporter. Proc. Natl. Acad. Sci. USA 88: 11168-71

von Heijne, G. 1983. Patterns of amino acids near signal-sequence cleavage sites. Eur. $J$. Biochem. 133: 17-21

von Heijne, G. 1986. The distribution of positively charged residues in bacterial inner membrane proteins correlatcs with the trans-membrane topology. EMBO J. 5: $3021-27$

Whitby, L. G., Axelrod, J., Weil-Malherbe, H. 1961. The fate of $\mathrm{H}^{3}$-norepinephrine in animals. J. Pharmacol. Exp. Ther. 132: 193-201

Winkler, H., Apps, D. K., Fisher-Collrie, R. 1986. The molecular functions of adrenal chromaffin granules: established facts and unresolved topics. Neuroscience 18: 26190

Yamada, K., Saltarelli, M. D., Coyle, J. T. 1988. Solubilization and characterization of a $\left[{ }^{3} \mathrm{H}\right] \mathrm{Hemicholinium-3}$ binding site in rat brain. J. Neurochem. 50: 1759-64

Yamamura, H. I., Snyder, S. H. 1973. High affinity transport of choline into synaptosomes of rat brain. J. Neurochem. 21: 1355-74

Yamauchi, A., Uchida, S., Kwon, H. M., Preston, A. S., Robey, R. B., et al. 1992. Cloning of a $\mathrm{Na}^{+}-$and $\mathrm{Cl}^{-}$-dependent betaine transporter that is regulated by hypertonicity. J. Biol. Chem. 267: 649-52

Yu, A. C. H., Chan, P. H., Fishman, R. A. 1986. Effects of arachidonic acid on glutamate and $\gamma$-aminobutyric acid uptake in primary cultures of rat cerebral cortical astrocytcs and ncurons. J. Neurochem. 47: 1181-89

Zaimis, E., Berk, L., Callingham, B. 1965. Morphological, biochemical and functional changes in the sympathetic nervous system of rats treated with NGFantiserum. Nature 206: 1221-22

Zaleska, M. M., Erecinska, M. 1987. Involvement of sialic acid in high-affinity uptake of dopamine by synaptosomes from rat brain. Neurosci. Lett. 82: 107-12 